\title{
Transbronchial needle aspiration cytology of endobronchial abnormalities: does it increase the positivity rates of bronchoscopy
}

\author{
Thapa $\mathrm{B}^{1}$, Sapkota $\mathrm{R}^{1}$, Shrestha $\mathrm{KR}^{1}$, Sayami $\mathrm{P}^{1}$, Sayami $\mathrm{G}^{2}$ \\ ${ }^{I}$ Manmohan Cardio-thoracic Vascular and Transplant Center, Institute of Medicine, Maharajgunj, Nepal. \\ ${ }^{2}$ Department of Pathology, Tribhuvan University Teaching Hospital, Institute of Medicine, Maharajgunj, Nepal.
}

\author{
Keywords: \\ Biopsy; \\ Brushing; \\ Lavage; \\ Transbronchial needle \\ aspiration; \\ Small cells; \\ Non-small cell.
}

\begin{abstract}
Background: Negative results in bronchoscopic sampling techniques increase costs and delay treatment. We analyzed if addition of transbronchial needle aspiration (TBNA) increases the diagnostic yield of bronchoscopy.

Materials and Methods: Patients with endobronchial abnormalities in whom a full set of sampling
techniques (lavage, TBNA, biopsy and brushing) were done and had a confirmed diagnosis of lung cancer
by one or more methods were included. The positivity rates of each of the sampling techniques and
their various combinations were studied. We compared the positivity rates of bronchoscopy with and
without TBNA. We also studied if TBNA was more valuable in any specific type, histology or position
of endobronchial abnormalities.

Results: The overall positivity rate of TBNA was $56 \%$. It was higher than lavage and brushing but lower than biopsy. The addition of TBNA to the routine combination of sampling tachniques (lavage, biopsy and brushing) increased diagnostic yield from $76 \%$ to $86.6 \%$. Contrary to previous reports, the increase in diagnostic yields did not differ significantly between types (exophytic vs submucosal), side or location of the endobronchial lesions. TBNA was found to have a significantly better positivity rates in small cell carcinoma than in non-small cell carcinoma cases.
\end{abstract}

Conclusion: TBNA is a safe sampling technique for endobronchial abnormalities during bronchoscopy. It increases the diagnostic yields of bronchoscopy and this increase seems to be uniform amongst different types, histologies and locations of endobronchial abnormalities.

\section{INTRODUCTION}

A variety of techniques like bronchoscopic lavage, brushing and biopsies have been used either alone or in combination to diagnose endobronchial abnormalities. Exophytic growths

\section{Correspondence:}

\section{Dr.Bibhusal Thapa}

Manmohan Cardio-thoracic Vascular and Transplant Center,

Maharajgunj, Kathmandu, Nepal.

Email: thapabibhusal@yahoo.com can be diagnosed with bronchoscopy with diagnostic yields close to $100 \% .^{1-4}$ However diagnosis is more difficult in submucosal or peribronchial tumours with routine bronchoscopic biopsy. ${ }^{2,4}$ The inability of the biopsy bites to reach the tumour tissue is the likely cause. ${ }^{5}$ Diagnostic ability of bronchoscopic biopsy can also often be limited in exophytic growths by the presence of necrotic cover on the growth. TBNA is an important adjunct bronchoscopic 


\begin{tabular}{|c|c|c|}
\hline Sampling technique/ combination & $\begin{array}{l}\text { Positivity } \\
\text { rates }\end{array}$ & Percentage \\
\hline Lavage & $11 / 75$ & 14.6 \\
\hline TBNA & $42 / 75$ & 56.0 \\
\hline Biopsy & $50 / 75$ & 66.6 \\
\hline Brushing & $25 / 75$ & 33.3 \\
\hline $\begin{array}{l}\text { Lavage }+ \text { Biopsy }+ \text { brushing (conven- } \\
\text { tional methods) }\end{array}$ & $57 / 75$ & 76.0 \\
\hline Conventional methods + TBNA & $65 / 75$ & 86.6 \\
\hline TBNA + Biopsy & $60 / 75$ & 80.0 \\
\hline Biopsy + Brushing & $57 / 75$ & 76.0 \\
\hline Biopsy + Lavage & $41 / 75$ & 54.6 \\
\hline TBNA + Biopsy + Brushing & $65 / 75$ & 86.6 \\
\hline
\end{tabular}

technique usually used in clinical staging of malignancy. ${ }^{5}$ However; it is not routinely used in the diagnosis of endobronchial lesions.$^{6-8}$ The present study was conducted to investigate if the addition of TBNA to the routine sampling techniques increases the chance of attaining a diagnosis of endobronchial lesions at bronchoscopy.

\section{MATERIALS AND METHODS}

The study was conducted prospectively in the Thoracic Surgery Unit, department of cardio-thoracic and vascular Surgery, Manmohan Cardio-Thoracic Vascular and Transplant Center, Institute of Medicine, Kathmandu, Nepal. Using non probability sampling all patients who met the inclusion criteria between August 2011 to April 2013 were included.

\section{Inclusion criteria:}

All patients with endobronchial abnormalities on bronchoscopy and who were subsequently confirmed to have a proven histological/cytological diagnosis of Lung cancer either on bronchoscopic sampling or by radiology guided FNAC/ biopsy.

\section{Exclusion Criteria:}

i) Patients in whom the full set of lavage, TBNA, biopsy and brushing could not be done for any reason

ii) Inadequate or unsatisfactory TBNA or biopsy as judged by the bronchoscopist

iii) Patients in whom histological /cytological diagnosis of lung cancer could not be proved by either bronchoscopy or subsequent radiological guided Fine Needle Aspiration Cytology (FNAC) or tru cut biopsy.
Table 2: Positivity rates in different types of endobronchial growths

\begin{tabular}{lccc}
\hline $\begin{array}{c}\text { Sampling techniques/ } \\
\text { combination }\end{array}$ & $\begin{array}{c}\text { Exophytic } \\
\text { growths }\end{array}$ & $\begin{array}{c}\text { Submucosal } \\
\text { growths }\end{array}$ & P value \\
\hline Lavage & $7 / 44(15.9 \%)$ & $4 / 31(12.9 \%)$ & 1.00 \\
TBNA & $26 / 44(59 \%)$ & $16 / 31(51.6 \%)$ & 0.63 \\
Biopsy & $31 / 44(71 \%)$ & $19 / 31(61.2 \%)$ & 0.46 \\
Brushing & $14 / 44($ & $11 / 31(35.4 \%)$ & 0.80 \\
Conventional methods & $36 / 44(81 \%)$ & $22 / 31(70.96 \%)$ & 0.61 \\
$\begin{array}{l}\text { Conventional methods } \\
\text { +TBNA }\end{array}$ & $40 / 44(90 \%)$ & $25 / 31(80.6 \%)$ & 0.63 \\
\hline
\end{tabular}

Table 3: Positivity rates in different types of endobronchial growths

\begin{tabular}{lcc}
\hline \multicolumn{1}{c}{ Histology } & Number (n) & Positivity (\%) \\
\hline Squamous & 54 & $28(52 \%)$ \\
\hline Small cell & 13 & $11(84 \%)$ \\
\hline Adenocarcinoma & 7 & $2(28 \%)$ \\
\hline Carcinoid & 1 & $1(100 \%)$ \\
\hline
\end{tabular}

\section{Methodology:}

The study was approved by the institutional review board of the Institute of Medicine (IOM) of Tribhuvan University. Informed consent was obtained from each patient. Awake bronchoscopy with Olympus BT-160 Video-bronchoscope was performed after $15 \%$ xylocaine spray. After the endobronchial lesion was noted, the samples were taken in the following sequence:

- Targeted lavage with $50 \mathrm{ml}$ normal saline

- TBNA $\geq 2$ passes into the lesion with a $22 \mathrm{G} 1 \mathrm{~cm}$ needle. Two slides were made of each pass. One of which was fixed in alcohol and the other was air dried.

- Biopsy $\geq 2$ good pieces were taken with $2 \mathrm{~mm}$ bronchoscopic biopsy forceps. They were fixed in formalin and sent for histopathological examination.

- Targeted brushing was done from the lesion. Two slides were made from the material. One was fixed in alcohol and the other air dried.

- The cytology and histology were examined by a team of experienced pathologists.

- The pathological reports were classified as:

- Positive for malignancy

- Suspicious for malignancy

- Negative for malignancy 


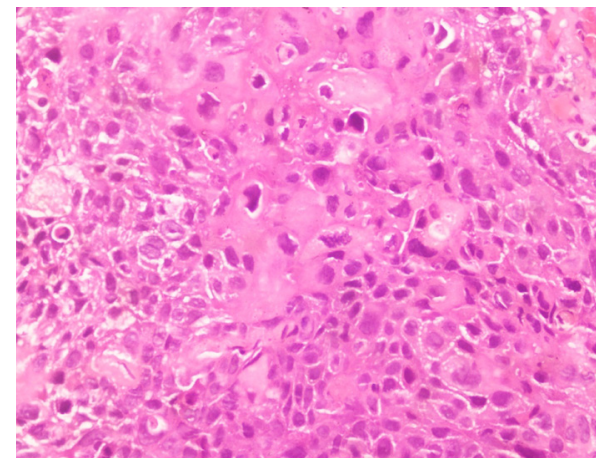

Figure 1: Photomicrograph showing squamous cell carcinoma with extensive keratinization of cytoplasm in bronchial biopsy(H E stain, X400).

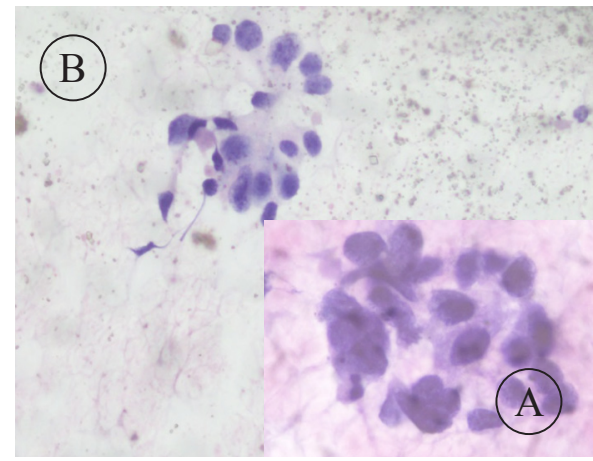

Figure 3: Adenocarcinoma, tumor cells forming glands, TBNA (Pap smear, X400). Inset: A malignant acinus in higher power (X1000).

If all the samples failed to give a diagnosis of Lung cancer, the patient was subjected to radiological (CT/USG) guided FNAC/ tru cut biopsy. Only patients who had a definite diagnosis of Lung Cancer by either one or more or the bronchoscopic samples or radiological FNAC/biopsy were included in the analysis. Those reported as suspicious were considered negative.

Data Analysis: The diagnostic rates of each of the sampling methods were expressed as a proportion of positive cases among total positives with different sampling methods. The statistical analysis was performed in SPSS (version 16), using Chi square tests for bivariate analyses and McNemar's test to compare different sampling techniques. P value of $\leq$ 0.05 was considered significant.

\section{RESULTS}

Between August 2011 and April 2013, there were 75 patients who had endobronchial abnormalities and in whom the full set of sampling techniques i.e. lavage, TBNA, biopsy and brushing were done. A positive diagnosis of cancer was attained by at least one or more bronchoscopic sampling techniques in 65 patients $(86.6 \%)$. In rest of the patients diagnosis was made by a radiologically guided (USG/CT) FNAC or tru-cut biopsy.

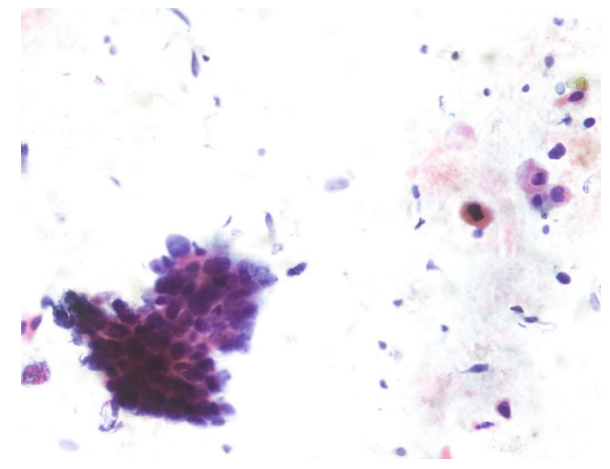

Figure 2: Squamous cell carcinoma showing tumor cell cluster and scattered keratotic atypical cells, bronchial brushing (Pap smear, X400).

Among them, 44 were deemed to have exophytic growths whereas 31 had submucosal growth. There were 45 left sided and 30 right sided lesions. The left main bronchus was the single commonest site. Squamous cell carcinoma (fig.1 \&2) was the commonest histology $(n=54,72 \%)$ followed by small cell $(n=13,17.3 \%)$ and adenocarcinoma $(n=7,9.3 \%)$ (fig.3). There was one case of carcinoid tumour. While there was almost equal numbers of exophytic and submucosal growth in non-small cell cancers (NSCLC), the lesions were overwhelmingly (11/13) exophytic in small cell cancers (SCLC).

Table 1 shows the diagnostic yields of each of the sampling techniques individually and in combinations. Biopsy gave highest positivity rates; TBNA was positive in nearly half while the diagnostic yield with bronchial lavage was very poor. Only TBNA was positive in eight patients. Addition of TBNA to the routine sampling techniques improved the diagnostic rates from $76 \%$ to $86.6 \%$. We compared the diagnostic yields of the sampling techniques in exophytic growths versus submucosal growths (Table 2). The diagnostic yield of bronchoscopy was better in exophytic growths as compared to submucosal growths. In either types biopsy yielded the highest positive results with TBNA following. Like all other sampling techniques, the positivity rate of TBNA was better for exophytic growths. However, this difference was not statistically significant $(\mathrm{P}=0.521)$.

The positivity rates was better amongst right sided tumors $(19 / 31,61 \%)$ as against left sided enobronchial abnormalities $(23 / 45,51 \%)$. This however did not reach statistical significance $(P=0.296)$. There were no significant differences in positivity between main (right+ left) versus lobar bronchial lesions $(15 / 24,60 \%$ Vs $27 / 51,52 \% \mathrm{P}=$ $0.437)$. There were also no significant differences between upper lobar versus middle and lower lobar lesions. The diagnostic yield was best in endobronchial lesions of right lower lobe (5/6). However, because the number was small, no inference could be drawn out of it.

When positivity rates of TBNA was compared between the different histologies, it was found to be best for SCLC. The 
rates amongst squamous cell carcinoma were moderate and they were poorest among patients with adenocarcinoma (Table3.). The positivity rates for SCLC was significantly better than that for NSCLC.The addition of TBNA increased the diagnostic rates from $83 \%$ to $89 \%$ in squamous cell cancers, $84 \%$ to $92 \%$ in small cell and $14 \%$ to $42 \%$ in adenocarcinomas.

We did not experience any complications attributable to the conduct of TBNA in any of our patients.

\section{DISCUSSION}

TBNA, as a diagnostic modality in endobronchial tumors is not widely used. British Thoracic Society (BTS) guidelines from 2001 recommend biopsies, brushings, and washings for sampling from visible lesions. TBNA was not included in the recommendation. ${ }^{9}$ The use of conventional TBNA and that of Endobronchial ultrasound (EBUS) -TBNA in staging of lung cancer and diagnosis of mediastinal masses is however well accepted. ${ }^{10-13}$ The utility of EBUS-TBNA to diagnose paren-chymal lesions in cases of non-diagnostic conventional bron-choscopy is being recognized and emerging. Several studies have been conducted to evaluate the usefulness of EBUS-TBNA for detecting malignancy in the parenchymal lesions locat $\neg$ ed adjacent to the central airways. $^{14}$

Unlike in some other reports, the diagnostic rate of TBNA in our series did not surpass bronchoscopic biopsy. ${ }^{5,15}$ Biopsy gave the highest yields in both types of lesions, all histologies and all locations. This corresponds with the findings of Roth et al. ${ }^{16}$

Our results showed that the addition of TBNA to the routine sampling techniques during bronchoscopy increases the diagnostic rates. Govert et al. in their series of 65 patients had found a $13 \%$ increase in the sensitivity which was statistically significant $(p=0.02) .{ }^{15}$ Buirski et al had also found a similar increase in their diagnostic rates upon addition of TBNA. ${ }^{5}$ In our series too there was a ten percent overall increase in diagnostic rate. These finding corroborate with previous reports.

Most previous reports have shown TBNA to be more useful in submucosal tumors than exophytic ones. ${ }^{17}$ Our results have demonstrated an increase in diagnostic rates of both exophytic and submucosal growths. The diagnostic rates were increased by a greater margin in exophytic lesions but the difference did not reach statistical significance. In exophytic growths, especially if there is a cap of necrotic tissue over the growth, the ability of a biopsy to sample representative viable tissue may be hampered. By virtue of deeper penetration allowed by the TBNA needle, it increases the chance of a positive diagnosis. ${ }^{1}$ This may be the reason that we saw a near equilavent increase in diagnostic rates in both types of lesions.
Previous reports 17 have suggested that addition of TBNA influences the diagnostic rates more in SCLC than in NSCLC, our findings showed TBNA to be more successful in SCLC $(\mathrm{P}=0.02)$ but there was a near uniform increase of diagnostic rates in all histologies.

This study was conducted prospectively with uniformity in the actual process of TBNA and other sampling techniques and clear cut criteria for positive and negative results. This helped minimize the variability often associated with retrospective studies. Because most patients did not undergo resection, a final histopathological result which is gold standard was absent. Thus calculation of sensitivity and specificity of TBNA and its comparison with other sampling techniques was not possible. This is a major drawback of this study.

\section{CONCLUSION}

TBNA by itself gives a moderate diagnostic yield. When added to the routine sampling techniques, it does increase the diagnostic rates of bronchoscopy for endobronchial lesions. This increase seems to be almost uniform for the different types of lesions, histologies and tumor locations.

\section{REFERENCES}

1. Kaçar N, Tuksavul F, Edipoğlu O, Ermete S, Güçlü SZ. Effectiveness of transbronchial needle aspiration in the diagnosis of exophytic endobronchial lesions and submucosal/peribronchial diseases of the lung. Lung Cancer. 2005;50:221-6. CrossRef

2. Arroliga AC, Mathay RA. The role of bronchoscopy in Lung Cancer. Clin Chest Med. 1993;14:87-98. PMid:8462250

3. Zavala DC. Diagnostic fibreoptic bronchoscopy:techniques and results of biopsy in 600 patients. CHEST 1975;68:12-9. CrossRef

4. Popovich J, Kvale PA, Eichenhorn MS, Radke JR, Ohorodnik JM, Fine G. Diagnostic accuracy of multiple biopsies from flexible fiberoptic bronchoscopy: a comparison of central versus peripheral carcinoma. Am Rev Respir Dis. 1982;125:521-3. PMid:7081810

5. Buirski G, Calverley PMA, Douglas NJ et al. Bronchial needle aspiration in the diagnosis of bronchial carcinoma. Thorax.1981;36:508-11. CrossRef

6. Wang KP, Terry PB. Transbronchial needle aspiration in the diagnosis of Bronchogenic carcinoma. Am Rev Respir Dis. 1983;127:344-7. PMid:6830056

7. Shure D, Fedullo PF. Transbronchial needle aspiration in the diagnosis of submucosal and peribronchial bronchogenic carcinoma. CHEST 1985;88:49-51. CrossRef

8. Gay PC, Brutinel WM. Transbronchial needle aspiration in the practice of bronchoscopy. Mayo Clin Proc 1989;64:158-62. CrossRef

9. Honeybourne D, Babb J, Bowie P et al. British Thoracic Society guidelines on diagnostic flexible bronchoscopy. Thorax 2001;56:I1I21. CrossRef

10. Medford AR, Bennett JA, Free CM, Agrawal S. Endobronchial ultrasound guided transbronchial needle aspiration. Postgrad Med J. 2010;86:106-15. CrossRef

11. Medford AR, Bennett JA, Free CM, Agrawal S. Mediastinal staging procedures in lung cancer: EBUS, TBNA and mediastinoscopy. Curr Opin Pulm Med. 2009;15:334-42. CrossRef

12. Yang H, Zhao H, Garfield DH, Teng J, Han B, Sun J. Endobronchial 
ultrasound-guided transbronchial needle aspiration in the diagnosis of non-lymph node thoracic lesion. Ann Thorac Med. 2013;8:14-21. CrossRef

13. Schwartz LE, Aisner DL, Baloch ZW et al. The diagnostic efficacy of combining bronchoscopic tissue biopsy and endobronchial ultrasound-guided transbronchial needle aspiration for the diagnosis of malignant lesions in the lung. Diagn Cytopathol. 2013;41:929-35. CrossRef

14. Verma A, Jeon K, Koh WJ et al. Endobronchial Ultrasound-Guided Transbronchial Needle Aspiration for the Diagnosis of Central Lung Parenchymal Lesions. Yonsei Med J 2013;54:672-8. CrossRef
15. Govert JA, Dodd LG, Kussin PS, Samualson WM. A prospective comparison of Fibreoptic Transbronchial Needle Aspiration and bronchial Biopsy for Bronchoscopically visible Lung Carcinoma. Cancer Cytopath 1999;87:129-34. CrossRef

16. Roth K, Hardie JA, Andreassen AH, Leh F, Eagan TML. Predictors of diagnostic yield in bronchoscopy: a retrospective cohort study comparing different combinations of sampling techniques. BMC Pulmonary Medicine 2008;8:2. CrossRef

17. Caglayan B, Akturk UA, Fidan A et al. Transbronchial Needle Aspiration in the diagnosis of Endobronchial Malignant Lesions: a 3-Year Experience. CHEST 2005;128:704-8. CrossRef 